\title{
Manamejen Pendidik dan Tenaga Kependidikan di TK Negeri Cempaka Jaya Pekalongan
}

\section{Retno Widiyastuti ${ }^{1}$ Asef Umar Fakhruddin ${ }^{2}$}

Guru Taman Kanak-Kanak Negeri Cempaka Jaya Pekalongan ${ }^{1}$ Prodi PGRA IAIN Purwokerto² $\underline{\text { retno.widiyastuti@gmail.com }}^{1}$ asefumar.fa@gmail.com $^{2}$

Tujuan penelitian ini adalah ingin mengetahui mengetahui manajemen pendidik dan tenaga kependidikan di Tk Negeri Cempaka Jaya Pekalongan dalam melaksanakan standar Nasional Pendidikan dengan harapan dapat memberikan kontribusi terhadap kualitas pendidikan secara keseluruhan. Metode penelitian yang digunakan adalah jenis penelitian kualitatif, tempat penelitian di TK Negeri Cempaka Jaya Pekalongan selama 4 bulan yaitu bulan maret sampai dengan bulan Juni 2017. Penelitian ini merupakan penelitian kualitatif dengan memakai teknik triangulasi data. Alat pemgumpulan data yang digunakan adalah dengan metode dokumentasi, wawancara, observasi, dan metode analisis data. Hasil penelitian ini adalah : (1) manajemen pendidik dan tenaga kependidikan di TK Negeri Cempaka Jaya dalam maksanakan standar Nasional Pendidikan, sehingga dapat memberikan kontribusi terhadap peningkatan terhadap kualitas pendidikan secara keseluruhan, (2) berdasarkan hasil wawancara dan observasi manajemen pendidik dan tenaga kependidikan dalam maksanakan standar Nasional Pendidikan di TK Negeri Cempaka Jaya Pekalongan sangatlah penting bagi kemajuan lembaga-lembaga PAUD.

Kata Kunci: manajemen, pendidik, tenaga kependidikan

The purpose of this study is to know know the management of educators and education personnel at Tk Negeri Cempaka Jaya Pekalongan in implementing the National Education standard in the hope of contributing to the quality of education as a whole. The research method used is the type of qualitative research, the research place in TK Negeri Cempaka Jaya Pekalongan for 4 months ie March until June 2017. This research is a qualitative research using triangulation data technique. Data collection tool used is the method of documentation, interviews, observation, and data analysis methods. The results of this study are: (1) management of educators and education personnel at TK Negeri Cempaka Jaya in maximal National Education standard, so as to contribute to improving the quality of education as a whole, (2) based on interviews and observations of management educators and education personnel in the maximization of National Education standard in Cempaka Jaya Pekalongan State Census is very important for the progress of PAUD institutions.

Keywords: management, educators, education personnel 


\section{PENDAHULUAN}

Manajemen sekolah yang profesional, diharapkan dapat memberikan kontribusi terhadap peningkatan kualitas pendidikan secara keseluruhan. Manajemen sekolah secara langsung akan mempengaruhi dan menentukan efektif tidaknya kurikulum. Dengan demikian, upaya peningkatan kualitas pendidikan harus dimulai dengan pembenahan manajemen pendidik dan tenaga kependidikan.Kualitas dan profesionalitas lembaga PAUD atau TK akan sangat tergantung pada latar belakang pendidikan dan pengalaman kepala PAUD, bidang keilmuan guru dan tenaga-tenaga profesional lainnya. Manajemen lembaga PAUD harus memperhatikan profesional dan kualitas, sehingga mampu memberi jaminan bagi terlaksananya kurikulum dengan baik. Oleh karena itu, untuk memberikan pelayanan yang baik dan berkualitas sesuai dengan kebutuhan pertumbuhan serta perkembangan anak, dalam pengelolaanya kita harus mengacu pada Permendiknas nomor 58 tahun 2009 tentang Standar Pendidikan Anak Usia Dini. Gaffar (1989) mengemukakan bahwa manajemen pendidikan mengandung arti sebagai suatu proses kerja sama yang sistematik, sistematis, dan komprehensif dalam rangka mewujudkan tujuan pendidikan nasional. Manajemen pendidikan juga dapat diartikan sebagai segala sesuatu yang berkenaan dengan pengelolaan proses pendidikan untuk mencapai tujuan yang telah ditetapkan, baik tujuan jangka pendek, menengah, maupun tujuan jangka panjang. Menurut Ordway Tead yang disadur oleh Drs. HE. Rosyidi dalam buku " Organisasi dan Management " mendefinisikan proses dan kegiatan pelaksanaan usaha memimpin dan menunjukkan arah penyelenggaraan tugas suatu organisasi di dalam mewujudkan tujuan yang telah ditetapkan.

\section{KAJIAN TEORI}

Menurut istilah, Nanang Fattah (2004) memberikan pengertian manajemen sebagai proses perencanaan, pengorganisasian, memimpin, dan mengendalikan upaya organisasi dengan segala aspeknya agar tujuan organisasi tercapai secara efektif dan efisien, Hersey Blanchard (dalam Reksohadiprojo, 1992) memberi batasan manajemen sebagai suatu usaha yang dilakukan dengan dan bersama individu dan kelompok untuk mencapai tujuan organisasi. Manajemen staf membahas tentang metode bagaimana menentukan jenis pembinaan, pelatihan, training yang diperlukan oleh pendidik dan tenaga kependidikan PAUD. Job description manajemen staf kelembagaan PAUD membahas tentang tugas masing-masing staf di dalam kelembagaan PAUD, mulai dari kepala PAUD, guru PAUD, staf administrasi , dan lain-lain. Senada dengan itu, dalam (Elfa, 2014) manajemen tenaga pendidik dan kependidikan bahwa perencanaan sumber daya manusia merupakan awal dari pelaksanaan fungsi manajemen sumber daya manusia. Dengan melakukan perencanaan ini, segala fungsi sumber daya manusia dapat dilaksanakan dengan efektif dan efisien. Ada beberapa metode yang dapat dipakai dalam merencanakan sumber daya manusia, antara lain :

\section{Metode Tradisional}

Metode ini biasanya disebut sebagai perencanaan tenaga kerja, semata-mata memperhatikan jumlah tenaga kerja serta jenis dan tingkat keterampilan dalam organisasi.

\section{Metode Perencanaan Terintegrasi}

Dalam perencanaan terintegrasi, segala aspek yng penting dalam pembuatan dan pencapaian visi organisasi ataupun sumber daya manusia turut diperhatikan. Dalam perencanaan terintegrasi segala perencanaan berpusat pada visi strtegik. Visi tersebut kemudian dijadikan standar pencapaian.

\section{Seleksi}

Seleksi didefinisikan sebagai suatu proses pengambila keputusan dimana individu dipilih untuk mengisi suatu jabatan yang didasrkan pada penilaian terhadap seberapa besar karakteristik individu yang bersangkutan, sesuai dengan yang dipersyaratkan oleh jabatan tersebut. 


\section{Manajemen Kinerja}

Manajemen kinerja tenaga pendidik dan kependidikan meliputi : (1) fungsi kerja esensial yang diharapkan oleh tenaga pendidik dan kependidikan, (2) seberapa besar kontribusi pekerjaan pendidik dan kependidikan bagi pencapaian tujuan pendidikan, (3) apa arti konkrit mengerjakan pekerjaan yang baik, (4) bagaimana tenaga kependidikan dan dinas bekerjasama untuk mempertahankan, memperbaiki maupun mengembangkan kinerja yang ada sekarang, (5) bagaimana prestasi kerja akan diundur, (6) mengenali berbagai hambatan kerja dan menyingkirkannya.

\section{Pemberian Kompensasi}

Program kompensasi atau balas jasa bertujuan untuk kepentingan perusahaan, karyawan, dan pemerintahan. Supaya tujuan dapat tercapai dan memberikan kepuasan bagi semua pihak hendaknya semua program pemberian didasarkan pada prinsip adil dan wajar. Tujuan pemberian kompensasi antara lain adalah sebagai ikatan kerjasama, kepuasan kerja, pengadaan efektifitas, motivasi, stabilitas, serta disiplin karyawan.

\section{METODE}

Metode penelitian menggunakan pendekatan kualitatif. Obyek penelitian disini efisiensi dan efektifitas manajemen pendidik dan tenaga kependidikan di TK Negeri Cempaka Jaya Pekalongan. Teknik pemeriksaan data yang memanfaatkan trianggulasi dengan sumber yaitu membandingkan data, mengecek kembali derajat kepercayaan suatu informasi yang diperoleh melalui waktu dan alat yang berbeda untuk dapat mengetahui adanya alasan-alasan terjadinya perbedaan tersebut.

Dalam analisis data ini penulis menggunakan cara yaitu analisis data kualitatif. Oleh karena itu, yang dilakukan penulis adalah dengan menggunakan metode kualitatif. Setelah semua data terkumpul selanjutnya data-data tersebut dimasukkan pada bagian pembahasan, untuk selanjutnya dilakukan penarikan kesimpulan yang didasarkan pada hal-hal pengolahan dan pembahasan data-data yang ada. Dalam metode pembahasan data ini penulis menggunakan cara yaitu pembahasan data kualitatif. Oleh karena itu penulisan yang dilakukan adalah penulisan kualitatif. Adapun dalam pembahasan data pada penelitian ini penulis menggunakan pembahasan menurut Nubermen yang dikutip Sugiyono (2008: 332) sebagaimana skema analisis berikut :

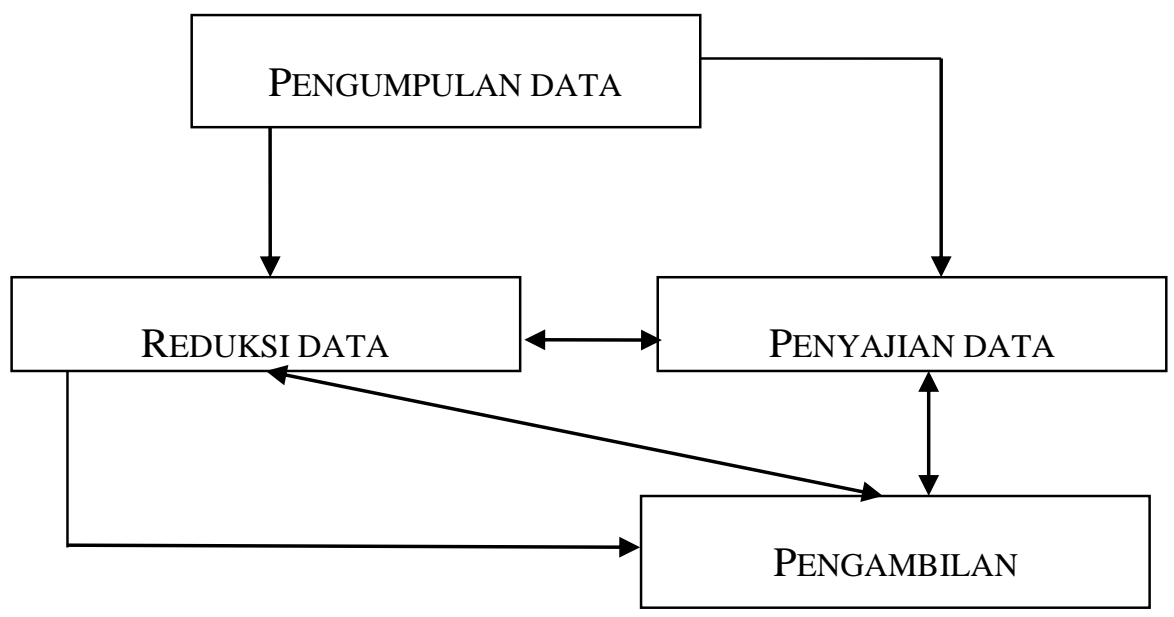

Gambar 1. Skema Analisis Data 
Dalam penganalisaan data menurut Huberman yang dikutip oleh Sugiyono (2008: 332) di atas dilakukan oleh penulis dimulai dari pengumpulan data yang kemudian direduksi dan disajikan sesuai pengumpulan data, selanjutnya data telah direduksi diolah dan dibahas dengan mengacu pada hasil deduksi data dan penyajian data untuk pengambilan kesimpulan hasil penelitian.

\section{HASIL PENELITIAN}

\section{Struktur Kurikulum}

Ruang lingkup Kurikuluim Tk dan RA berdasarkan keputusan Direktur Jenderal Pendidikan Dasar dan Menengah Departemen Pendidikan Nasional nomor 399a/C.C2/Kep/DS/2004 tertanggal 2 Agustus 2004.

Tabel 1. Komponen Struktur Kurikulum

\begin{tabular}{|c|c|c|c|}
\hline \multirow{3}{*}{ NO } & \multirow{3}{*}{ Komponen } & \multirow{2}{*}{\multicolumn{2}{|c|}{$\frac{\text { Alokasi Waktu / Jam Pelajaran (30 menit) }}{\text { Kelompok }}$}} \\
\hline & & & \\
\hline & & A & $\mathrm{B}$ \\
\hline \multirow[t]{3}{*}{ A } & Pembiasaan & & \\
\hline & 1. Moral dan Nilai-Nilai Agama & 2 jam & 2 jam \\
\hline & 2. Sosial, Emosional, dan Kemandirian & 4 jam & 4 jam \\
\hline \multirow[t]{10}{*}{$\mathrm{B}$} & $\begin{array}{l}\text { Bidang } \\
\text { Dasar }\end{array}$ & & \\
\hline & 1. Berbahasa & 6 jam & 6 jam \\
\hline & 2. Kognitif & $6 \mathrm{jam}$ & 6 jam \\
\hline & 3. Fisik Motorik & 6 jam & 6 jam \\
\hline & 4. Seni & $6 \mathrm{jam}$ & 6 jam \\
\hline & 5. Mulok & & \\
\hline & $\begin{array}{l}\text { a. BTQ ( pengenalan huruf hijaiyah, } \\
\text { hafa- }\end{array}$ & 3 jam & 3 jam \\
\hline & lan do'a-do'a harian dan surat-surat & & \\
\hline & Pendek ) & & \\
\hline & b. Pengenalan Bahasa Inggris & & 1 jam \\
\hline \multirow[t]{6}{*}{$\mathrm{C}$} & Pengembangan diri & & \\
\hline & 1. Seni Tari & 2 jam & 2 jam \\
\hline & 2. Seni Lukis/ mewarnai gambar & 2 jam & 2 jam \\
\hline & 3. Senam & 2 jam & 2 jam \\
\hline & 4. Drumband & - & 2 jam \\
\hline & Jumlah & $\begin{array}{l}39 \text { jam } \\
(1170 ~\end{array}$ & 42 jam (1260 menit) \\
\hline
\end{tabular}

\section{Muatan Kurikulum}

Muatan KTSP meliputi sejumlah bidang pengembangan yang keluasan dan kedalamannya merupaka beban belajar bagi peserta didik pada satuan pendidikan. Di samping itu muatan materi muatan lokal dan pengembangan diri termasuk kendala isi kurikulum.

Peraturan Pemerintah Nomor 19 Tahun 2005 tentang Standar Nasional Pendidikan menegaskan bahwa kedalaman muatan kurikulum pada setiap satuan pendidikan dituangkan dalam kompetensi pada setiap tingkat-tingkat dan atau semester sesuai dengan Standar Nasional Pendidikan. Kompetensi yang dimaksud terdiri atas standar kompetensi dan kompetensi dasar. 


\section{Bidang Pengembangan Pembiasaan}

Bidang pengembangan pembiasaan merupakan kegiatan yang dilakukan secara terus menerus dan ada dalam kehidupan sehari-hari anak sehingga menjadi kebiasaan yang baik. (1) aspek perkembangan moral dan nilai-nilia agama, bertujuan untuk meningkatkan ketakwaan terhadap Tuhan Yang Maha Esa dan membina sikap anak dalam rangka meletakkan dasar agar anak menjadi warga negara yang baik. (2) aspek perkembangan sosial, emosional dan kemandirian, dimaksudkan untuk membina anak agar dapat mengendalikan emosinya secara wajar dan dapat berinteraksi dengan sesamanya maupun dengan orang dewasa dengan baik serta dapat menolong dirinya sendiri dalam rangka kecakapan hidup. Bidang Pengembangan Kemampuan Dasar.

\section{Muatan Lokal}

Baca Tulis Al Qur'an, tujuan: (1) mengenalkan huruf Hijaiyyah, surat-surat pendek dalam Al Qur'an, dan doa-doa harian sejak dini, (2) meningkatkan Iman dan Takwa kepada Alla SWT sejak dini. Bahasa Inggris, tujuan : (1) mengenalkan Bahasa Inggris sederhana sejak dini, (2) pengembangan diri, (3) mengembangkan kreatifitas anak di bidang fisik motoric, (3) mengembangkan kreatifitas di bidang seni, (4) meningkatkan apresiasi anak terhadap fisik motorik dan seni

\section{Pengaturan Beban Belajar}

Beban belajar yang digunakan adalah sistem paket sebagaimana tertera dalam struktur kurikulum, yaitu:

Tabel 2. Pengaturan Beban Mengajar.

\begin{tabular}{llllll} 
Kelas & $\begin{array}{l}\text { Satu Jam Pembelajaran } \\
\text { Tatap Muka/ Menit }\end{array}$ & $\begin{array}{l}\text { Jumlah } \\
\text { Pembelajaran } \\
\text { Minggu }\end{array}$ & $\begin{array}{r}\text { Jam } \\
\text { Per }\end{array}$ & $\begin{array}{l}\text { Minggu } \\
\text { Per Tahun Ajaran }\end{array}$ & $\begin{array}{l}\text { Wemtif } \\
\text { Pembelejaran } \\
\text { (Jam) Per Tahun }\end{array}$ \\
\hline A & 30 menit & 39 jam & 34 minggu & 1326 jam \\
\hline B & 30 menit & 42 jam & 34 minggu & 1428 jam
\end{tabular}

\section{Keterlibatan Pendidik dan Tenaga Kependidikan dalam pencapaian Visi dan Misi}

Hasil wawancara dengan Kepala sekolah Bapak Abdul Cholik, S.Pd mengatakan "TK Kami mempunyai Visi dan Misi. Visinya adalah "Terbentuknya peserta didik yang beriman, bertakwa, berilmu, mandiri jasmani dan rohani”. Dan misi yang Kami coba disini adalah: (1) menanamkan agama dan moral Pancasila menuju terbentuknya pribadi peserta didik yang beriman dan bertakwa, (2) memberikan Pendidikan keterampilan untuk memiliki prestasi dalam bidang seni dan olah raga, (3) memberikan tugas-tugas yang mengarah pada terbentuknya pribadi anak yang mandiri, (4) memberi dasar pengetahuan agar dapat tumbuh kembang sesuai dengan tahap perkembangannya. Maksudnya adalah agar anak-anak memiliki keimanan terhadap Tuhan Yang Maha Esa untuk landasan kehidupan, kemandirian, melaksanakan kegiatan tanpa bantuan dari orang lain, serta sehat jasmani dan rohani melalui sarana dan prasrana yang ada.

Tujuan yang ingin dicapai di TK Kami adalah mengacu pada tujuan Pendidikan Nasional yaitu membantu anak didik mengembangkan berbagai potensi baik psikis maupun fisik yang meliputi moral nilai-nilai agama, sosial emosional, kognitif, bahasa, fisik motorik, kemandirian dan seni untuk siap memasuki pendidikan dasar. Strategi yang kami gunakan dalam mencapai tujuan tersebut adalah menanamkan agama dan moral Pancasila kapada anak didik menuju terbentuknya pribadi peserta didik yang beriman dan bertakwa melalui kegiatan baca tulis Al Qur'an, memberikan Pendidikan keterampilan untuk memiliki prestasi dalam bidang seni dan olah raga, memberikan tugas-tugas yang mengarah pada terbentuknya pribadi anak yang mandiri, memberi dasar pengetahuan agar dapat tumbuh kembang sesuai dengan tahap perkembangannya dengan menggunakan metode yang bergantian. 


\section{Manajemen Pendidik dan Tenaga Kependidikan \\ Rekruitmen}

Perekrutan tenaga pendidik dan kependidikan di TK kami, karena TK kami adalah TK Negeri maka untuk tenaga PNSnya diberikan langsung dari Dinas Pendidikan. Sedangkan untuk tenaga non PNS melalui pengumuman penerimaan tenaga kerja, lalu setelah ada pendaftarnya dilaksanakan tes secara langsung. Tes yang kami lakukan adalah tes tertulis, wawancara, dan menampilkan bentuk ketrampilan atau kreativitas masing-masing semacam membuat alat permainan edukatif.. Setelah semua peserta melakukan tes maka untuk menentukan siapa yang akan diterima adalah dengan memberikan penilaian terhadap proses tes tersebut, dan bagi yang nilainya tertinggi maka orang tersebut yang akan diterima menjadi tenaga kerjan.

\section{Penempatan}

Penempatan tenaga kerja di TK kami disesuiakan dengan kebutuhan dan kemampuan masing-masing pegawai dan juga dari kiprah yang dilakukan.

\section{Penilaian}

Cara menilai kualitas pendidik dan tenaga kependidikan di TK kami adalah dengan diadakan supervisi kela yang dilaksanakan setiap bulan sekali dan penilaian langsung dengan pengamatan kinerja seharihari.

\section{Pembinaan}

Terdapat pembinaan khusus yang dilakukan pada setiap rapat koordinasi yang ada di TK dengan cara saring antara satu dengan yang lain. Bentuk-bentuk pembinaan yang kami lakukan adalah melalui kegiatan rapat baik yang dilakukan di TK dan dalam pertemuan-pertemuan rutin gugus maupun dalam pertemuan IGTKI. Juga ada pembinaan-pembinaan dari pengawas yang memang sengaja kami undang dalam rapat. Dalam pelaksanaan pembinaan tersebut memang adakalanya kami mengalami kendalakendala. Dan untuk dapat mengatasi kendala-kendala tersebut, kami selalu memberikan contoh bentuk perlakuan nyata untuk memancing para tenaga pendidik dan kependidikan agar mengikuti atau merubah kesalahannya. Misalnya ketika ada kegiata olah raga setiap hari jum'at, pada waktu yang telah ditentukan kegiatan tersebut tidak segera dilaksanakan, maka kami langsung turun lapangan untuk mengajak anak-anak berolahraga, secara otomatis guru yang bertugas akan ssegera ikut turun ke lapangan. Tenaga pendidik dan kependidikan di TK kami memang mendapatkan pelatihan-pelatihan melalui kegiatan gugus yang dilakukan setiap dua minggu sekali. Karena secara kebetulan TK ini dijadikan gugus inti, maka kami selalu ikut menjadi bagian dari pengisi materi. Selain itu juga kami mengikuti diklat yang diselenggarakan baik di tingkat propinsi maupun di tingkat kota, tapi yang dikirim incidental yang rutin dalam kegiatan gugus secara bergantian disesuikan dengan tema diklatnya. Berdasar kriteria penilaian audit eksternal oleh BAN PNFI, TK ini sudah memenuhi standar Nasional Pendidikan yang tercantum dalam permendiknas Nomor 58 Tahun 2009 dengan bukti akreditasi dengan perolehan nilai A.

\section{DISKUSI}

Dalam pengamatan ini difokuskan untuk mengetahui efisiensi dan efektifitas manajemen pendidik dan tenaga kependidikan pada TK Negeri Cempaka Jaya Pekalongan. Oleh karena itu dalam melaksanakan pengamatan seluruh data dikumpulkan untuk memperoleh jawaban atas permasalahan tersebut. Berdasarkan deskripsi hasil penelitian tentang Manajemen Pendidik dan Tenaga Kependidikan dapat dianalisa sebagai berikut :

\section{Perencanaan}

Perencanaan Pendidik dan Tenaga kependidikan di TK Negari Cempaka Jaya disesuaikan dengan kebutuhan tenaga baik pendidik maupun tenaga kependidikan yang ada melalui prosedur yang ada di TK Negeri Cempaka Jaya Pekalongan. 


\section{Perekrutan}

Proses perekruktan pendidik dan tenaga kependidikan di TK Negeri Cempaka Jaya adalah melalui pemasangan pengumuman tentang kebutuhan tenaganya, kemudian melalui seleksi dengan cara diadakan tes secara tertulis, wawancara, dan presentasi hasil ketrampilan yang dimiliki oleh pekamar.

\section{Penempatan}

Penempatan pendidik dan tenaga kependidikan di TK Negeri Cempaka Jaya Pekalongan disesuaikan dengan kemampuan dan kiprah yang telah dilakukan.

Penilaian

Penilaian kerja pendidik dan tenaga kependidikan di TK Negeri Cempaka Jaya Pekalongan dilakukan dengan mengadakan supervisi setiap bulan sekali kepada para pendidik dan tenaga kependidikan.

\section{Pembinaan}

Pembinaan yang dilakukan di TK Negeri Cempaka Jaya dilakukan secara terus menerus melalui kegiatan-kegiatan baik yang diadakan disekolah itu maupun di sekolah lain, serta dari pengawas pendidikan daerah setempat.

\section{Pendidikan dan Pelatihan}

Pendidik dan Tenaga kependidikan di TK Negri Cempaka Jaya Pekalongan mendapatkan pelatihanpelatihan melalui kegiatan gugus, diklat, dan seminar-seminar yang diadakan baik di tingkat propinsi maupun di tingkat kota secara bergantian sesuai dengan kemampuan peserta yang akan dikirim dan tema diklat itu sendiri. Berdasarkan analisa data tersebut maka dapat ditarik kesimpulan bahwa efisiensin dan efektifitas pendidik dan tenaga kependidikan di TK Negeri Cempaka Jaya dianggap sudah sesuai dengan standar Nasional Pendidikan yang diamanatkan oleh pemerintah dalam Permendiknas niomor 58 tahuhn 2009 pasal 1 ayat (1) da (2) tentang standar Pendidikan Anak Usia Dini, dimana didalamnya terdiri dari atas standar tingkat pencapaian perkembangan, standar pendidik dan tenaga kependdidikan, standar isi, proses, dan penilaian, serta standar sarana dan prasarana, pengelolaan, dan pembiayaan yang dibuktikan dengan hasil akreditasi dari badan akreditasi propinsi dengan nilai A. Hal tersebut juga dipengaruhi oleh faktor- faktor antara lain :

\section{Faktor Pendukung}

Faktor yang mendukung tercapainya efisiensi dan efektivitas manajemen di TK Negeri Cempaka Jaya Pekalongan karena semua sarana dan prasarana yang ada baik APE maupun sarana yang lain sudah cukup memadai, juga didukung oleh kualifikasi pendidikan tenaga pendidik yang sudah memenuhi persyaratan yang ditetapkan oleh pemerintah.

\section{Faktor Penghambat}

Faktor penghambat yang ada kalanya dialami TK Negeri Cempaka Jaya dalam pencapaian efisiensi dan efektifitas manajemen pendidik dan tenaga kependidikan adalah didalam pelaksanaan kegiatan yang telah diprogramkan adakalanya tidak tepat waktu. Namun hal itu dapat diatasi dengan baik.

\section{KESIMPULAN}

Hasil penelitian yang dapat diambil adalah sebagain berikut:

(1) Manajemen pendidik dan tenaga kependidikan di TK Negeri Cempaka Jaya dalam maksanakan standar Nasional Pendidikan, sehingga dapat memberikan kontribusi terhadap peningkatan terhadap kualitas pendidikan secara keseluruhan,

(2) berdasarkan hasil wawancara dan observasi manajemen pendidik dan tenaga kependidikan dalam maksanakan standar Nasional Pendidikan di TK Negeri Cempaka Jaya Pekalongan sangatlah penting bagi kemajuan lembaga-lembaga PAUD. 


\section{REFERENSI}

Ajeng Yusrina,2012. Kiat-Kiat Menjadi Guru PAUD yang Disukai Anak-Anak. Jogjakarta: Diva Press Lexy.J.Moleong, M.A. 2987-2007. Metode Penelitian Kualitatif. Bandung: Pt. remaja Rosdakarya Martuti, 2009. Mendirikan dan Mengelola PAUD. Bantul: Kreasi Wacana

Mulyasa. 2007. Manajemen Berbasis sekolah. Bandung: PT Remaja Rosdakarya Offset Sugiyono, 2007. Metode Penelitian Pendidikan. Bandung:Alfabeta Suharsini Arikunto.2006 Prosedur Penelitian. Jakarta: PT. Rineka Cipta.

Sutikno,M. Sobry. 2012. Manajemen Pendidikan.Lombok : Holistika Suyadi, 2011. Manajemen PAUD. Yogyakarta: Pustaka Belajar Yuviarti, 2009. Materi Pokok Profesionalitas Guru AUD. Jakarta: Universitas Terbuka 